assessment. To the question: "Could TA have helped?" he says yes, in many of the cases it could have avoided both the hazard and the 'social shock' produced by publicity about the hazard. The second of these is harder to achieve than the first, because once the issue gets into a storm of controversy the responsible authority is driven to make crisis-decisions (as were made when some American States banned phosphate from detergents in the belief that nitrilo-triacetate (NTA) would be a safe substitute, although NTA is a chelating agent which might bring heavy metals into solution, and is a suspect carcinogen.)

One of the many lessons to be learnt from this book is the essential part played by the mass media in the ignition of public opinion about hazards arising from technological developments. In the popular press sober truth has to be sacrificed to circulation, the reservations have to be stripped off the expert's statement. "On the whole", writes Lawless, "the news media have not done a particularly creditable job of reporting scientific and technological events to the public over the last thirty years. They tend to overdo the bizarre or the scare aspects at the beginning of a case and seldom follow through to summarise adequately the resolution of an issue". Yet the news media are the main channel of communication between the mass of the public and the people who are responsible for getting the facts right and making the decisions.

\section{Evoked potential investigations}

Progress in Clinical Neurophysiology. Vol. 1: Attention, Voluntary Contraction and Event-Related Cerebral Potentials. Edited by J. E. Desmedt. Pp.256. (S. Karger: Basel, 1978.) SFr./DM98; $\$ 43.75$.

THE title of this book, the first volume in a series based on a symposium held in Brussels in April 1974, will mislead those looking for papers on evoked potential correlates of attention in humans. This topic will be dealt with in volume 6 . In the meantime, most of the papers in this volume demonstrate the ingenuity of both experimental design and data analysis required to further our knowledge of evoked potential correlates of behaviour.

The opening chapter contains important recommendations on publication criteria for evoked potential studies, and as such ought to have been published in an appropriate jour-
The author of this book would not wish his preliminary study to be taken as a sufficient basis for generalisations about the social impact of technology. But I venture to draw three provisional conclusions from Technology and Social Shock. Industrialists are tempted (though some resist the temptation) to put profits before the protection of society. (Lawless wryly reminds us that the motor manufacturers in Detroit continue to make cars with speedometers which register up to $120 \mathrm{mph}$ "even as speed limits are being reduced to fifty five miles an hour across the country.") Government officials and politicians are tempted to play safe over hazards; witness the nonsensical consequences which sometimes follow the application of the Food, Drug, and Cosmetic Act Amendment of 1958the notorious 'Delaney Clause'. Editors and science reporters are tempted (though some resist the temptation) to put sales above sobriety when they report hazard-stories. It is for scientists to make technology assessments, but if the assessments are to be of any practical value, industry, government, and the press will have to learn to make better use of the assessments than they do at present. And the assessments themselves need to be frequently revised. They can never be more than intelligent guesses and they will often be wrong, but, as this important book demonstrates, it is worthwhile to persist with them.

Lord A shby is a Fellow of Clare College. Cambridge, and Chancellor of the Queen's University, Belfast.

nal with a wider readership than this book will achieve. This chapter and the second, on evoked potential methodology in general, are relevant to a wider range of evoked potential investigations than are covered in the remainder of the book. The description of the methodology could have been oriented more towards the specific problems of recording the various slow potential shifts that are described in the remaining papers.

The main theme of the remaining papers concerns the scalp topography of slow potential shifts in man and their occurrence in identifiable brain mechanisms in animals. Important results include the differences in slow potential distribution during the sensory and motor phases of a task and the smaller hemispheric asymmetries seen for left-handers compared with right-handers in a variety of motor activities.

Geoff Barrett

Geoff Barrett is a Member of the MRC External Staff working at The National Hospital, London, UK.

\section{Polymerisation chemistry}

Polymerization Processes. Fdited by C. E. Schildknecht and 1. Skeist. Pp. 768. (Wiley: London and New York. 1978.) $£ 27$.

THIS volume is the latest of an authoritative and highly respected series of monographs in polymer science and is an updated and much revised version of the earlier Polymer Processes published in 1956.

The flavour and emphasis of the book is perhaps best illustrated by the fact that of the twenty-nine contributing authors only six are from academic institutions, the remaining twenty-three being associated with industrial organisations. The result is a book which gives an extensive and well balanced view of polymerisation chemistry with a very distinct and intentional bias towards the technological side of its subject.

Of the nineteen chapters, eight are directly concerned with step-reaction polymerisation and ten with addition polymerisation, the remaining chapter dealing with photochemically induced polymerisation and cross-linking reactions. The result is to provide a good account of the chemistry of all of the industrially important polymerisation processes coupled with a discussion of the way in which these processes are applied in commercial practice.

As an academic polymer scientist I found this book extremely interesting and stimulating. The account of basic chemistry is well done and comprehensive, and carcful editing has ensured that a uniformly high standard is maintained. However. much of this material is available elsewhere and the most useful aspect of the book is undoubtedly the successful way in which the adaption of chemistry to production scale processes is described. Most of the major commercial processes are covered, including both conventional melt, emulsion and suspension systems. and the more modern techniques such as bulk polymerisation of vinyl chloride.

This book should find ready acceptance among those who teach polymer science and wish to have a more practical account of their subject than that given in more conventional texts. It is uniformly well written, and although there are minor typographical errors the overall impression is of careful proof-reading and editing.

N. C. Billingham

N. C. Billingham is Lecturer in Chemistry at the University of Sussex. UK. 